\title{
Cationic Gold-Catalyzed Cyclization of Diynamides
}

Category

Metal-Catalyzed

Asymmetric

Synthesis and

Stereoselective

Reactions

\section{Key words}

gold

cyclo-isomerization

pyrrolidines
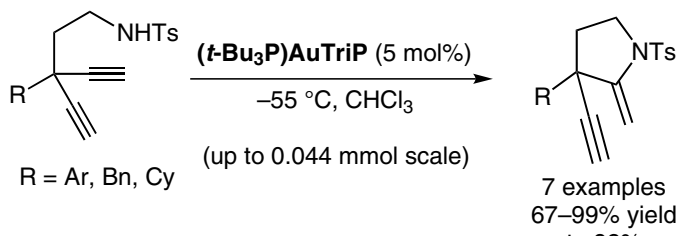

$-99 \%$ yield up to $92 \%$ ee

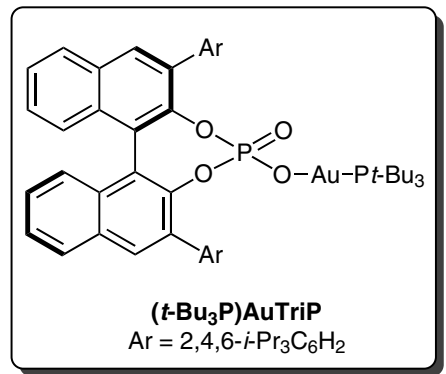

Significance: The authors report an enantioselective cycloisomerization of diynamides to methylene pyrrolidines catalyzed by cationic gold with optically active binol phosphates as counteranions. This work was inspired by Toste and coworkers' application of chiral counterions in goldcatalyzed functionalization of allenes (Science $\mathbf{2 0 0 7}, 317,462)$. The chiral pyrrolidine products formed are highly valuable as they contain an allcarbon-substituted quaternary stereocenter and are difficult to prepare in enantiomerically pure form by other conventional methods.
Comment: Czekelius and co-workers had previously demonstrated that cationic gold complexes cyclize diynols and diynamides to the corresponding unsaturated heterocycles in good yield (Chem. Eur. J. 2009, 15, 13323). However, optically active phosphine and carbene ligands gave poor enantioselectivity due to the linear coordination geometry in gold(I)-alkyne complexes. The use commercially available binol phosphates as chiral counterions overcomes this problem and allows for high enantioselectivity in the cyclization. The best results were obtained in chlorinated solvents at low temperatures, which is in line with the contact ion pair model of the cationic gold-alkyne complex and the anionic chiral phosphate. 